\title{
DEVELOPING AN ARCHITECTURE FOR AN INTERNSHIP VIRTUAL MARKETPLACE SYSTEM
}

\author{
Ruidong Zhang, University of Wisconsin-EauClaire, zhangr@uwec.edu
}

\begin{abstract}
An Internship Virtual Marketplace System (IVMS) attempts to overcome the limitations of traditional college internship management programs to enable students to gain sufficient practical skills or knowledge before they start their first job. It is a vehicle for effective allocation of internship/job opportunities on a large scale (e.g., state-wide). It is a life cycle management approach used for internships in the cyberspace, from initial internship postings, student applications, to automated and intelligent data mining and match making, to day by day internship supervising and reporting, to the end of the internship. An IVMS system will be designed to be efficient, automated, low cost, and more effective matching of internship opportunities with students' knowledge and skills. IVMS will be dynamic. As soon as new data is entered to the system, the virtual marketplace (the data mining process) will be started. IVMS is a data warehouse with OLAP capability. As such, data can be mined along multiple dimensions. Different data cubes can be created. Given the complexity of IVMS, a prototype will need to be developed as a proof of concept before committing sufficient resources to start a large scale implementation of IVMS. The expected benefits can be substantial.
\end{abstract}

Keywords: Internship Virtual Marketplace System (IVMS), traditional internship management and life cycle Internship management

\section{INTRODUCTION}

The importance of a student gaining internship experience cannot be overemphasized. A study conducted a survey of 185 employers of 392 interns enrolled in an AACSB-accredited business college in a Northeastern US university, and the survey results indicate significantly more full-time opportunities for undergraduates with internship experience; and interestingly, even average-performing interns were significantly more likely to receive full-time job offers than non-interns, and high-performing interns were more likely to receive higher starting salaries [2].

However, traditional student internship management is usually handled discretely on each campus and has many limitations or problems. These limitations include distance, physical locations, duration, fixed or non-flexible starting time (typically done during summer break), high cost, and late stage student status (summer internships typically offered to junior or senior students). The real consequence is that a student may not have ideal internships or cannot gain sufficient practical skills or knowledge before they start their first job.

With advances in information technology, big data evolution and market design theory, an Internship Virtual Marketplace System (IVMS) is providing a promising solution to the problems facing the traditional internship management programs. It allows students to tap internship opportunities regardless of distance, physical location, timing or duration. It attempts to overcome the limitations of traditional discrete internship management programs to enable students to gain sufficient practical skills or knowledge before they start their first job.

\section{TRADITIONAL INTERNSHIP MANAGEMENT PROGRAM: LIMITATIONS}

Traditional internship management programs are passive, non-dynamic and less efficient. The weakness or limitations of traditional internship management programs can be identified and organized into the following areas:

- Physical location limitation

- Distance limitation

- Monitoring and reporting limitations

- Time restrictions

- restrictions on student academic standing requirements

- Duration of internship restrictions (can be of any length) 
- Automated student-internship match-making

- Non-Adaptability

- restriction on size of internship project (need to cover the entire summer break)

- $\quad$ Cost (most need to be paid)

IVMS, compared with the traditional internship management programs, attempts to overcome the weakness or limitations of traditional internship management programs. An IVMS system is intended to be efficient, automated, low cost, and more precise matching of internship opportunities with students' knowledge and skills. Unlike traditional campus career service web site or many commercial job sites such as monster.com and www.indeed.com, the IVMS is active and vigilant instead of passive; it is full life cycle instead of just a skill matching; it is more affordable to employers and students in that training, supervising, reporting, project evaluating, short term employment, and payroll can all be done virtually.

\section{AN INTERNSHIP VIRTUAL MARKETPLACE SYSTEM (IVMS): DEFINED}

The IVMS is a life cycle management of internships in the cyberspace. It is a vehicle for effective allocation of internship/job opportunities on a large scale (e.g., state-wide). It emphasizes the life cycle implementation of internships in the cyberspace, from initial internship postings, student applications, to automated and intelligent data mining and match making, to day by day internship supervising and reporting, to the end of the internship. On the other hand, an IVMS is needed for multiple academic disciplines (especially those specialty-oriented disciplines such as medical, biological, pharmaceutical) to balance the supply and demand or solve the supply-demand crisis [3].

The theoretical foundation of the IVMS is the latest "market design" theory applied to the practice of studentinternship match-making [1]. An essential and successful aspect of modern market design theory is the efficient and effective resource allocation without involving money and prices.

Technology wise, the IVMS is designed based on modern database, data warehousing, and data mining theory and technologies, as well as the advances in multi-platform end-user devices and the mobile Internet. The challenges to overcome are data integration, data modeling and data mining algorithms. The big data revolution and ubiquitous computing are providing the needed eco-system for the IVMS system to grow. It has become practical to create a central internship data warehouse to support the creation of a large scale state-wide virtual internship marketplace.

\section{IVMS: THE MAIN FUNCTIONALITIES}

An IVMS system will be designed to be efficient, automated, low cost, and more effective matching of internship opportunities with students' knowledge and skills. Given the complexity of IVMS, a prototype will need to be developed as a proof of concept before committing sufficient resources to start a large scale implementation of IVMS.

The IVMS is a large scale system. It aims at the effective resource allocation on a large scale. It is scalable and the scalability must be very good.

IVMS will be dynamic. As soon as new data is entered to the system, the virtual marketplace (the data mining process) will be started.

IVMS is a data warehouse with OLAP capability. As such, data can be mined along multiple dimensions. Different data cubes can be created.

\section{AN ILLUSTRATION OF THE ARCHITECTURE OF AN IVMS}




\section{Issues in Information Systems}

Volume 14, Issue 1, pp.307-310, 2013

Traditional internship management systems are not intelligent, not automated, not dynamic and passive in nature. On the other hand, the IVMS is active and vigilant. The following diagram describes the architectural components of the IVMS for the IVMS Marketplace Space.

*ETL: extraction, transformation, and load

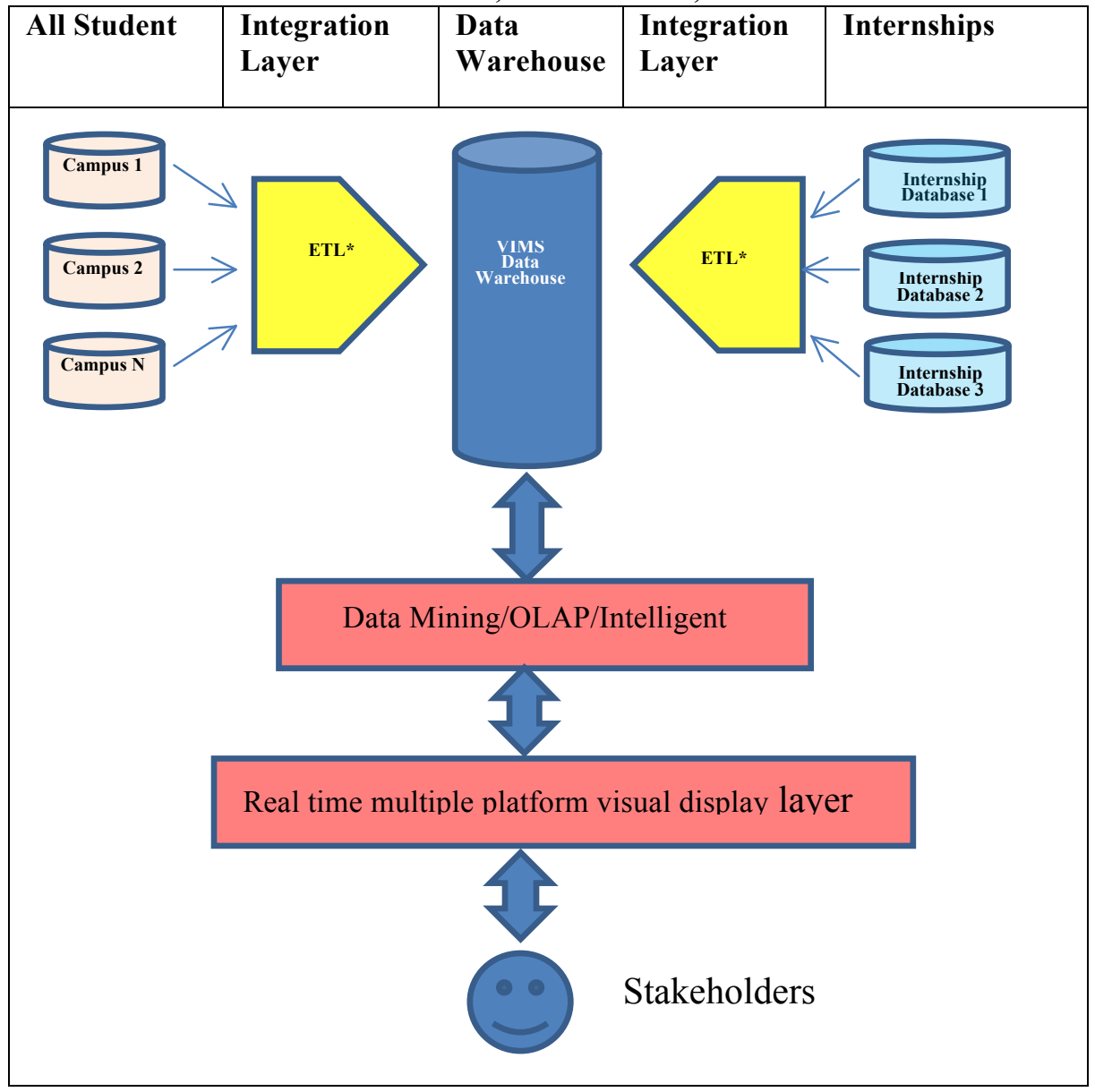

\section{CONCLUSIONS}

Overall, the IVMS is designed to integrate the discrete and smaller internship listing databases (located in each campus) in to a central data warehouse to achieve effective and efficient resource allocation on a large scale. In microeconomics, this is called the economies of scale. A successfully implemented virtual internship marketplace system (IVMS) has the potential to balance the supply and demand as well as increasing the chance a student being employed.

The expected benefits can be substantial. The direct benefit or economic impact would be the well prepared college graduates who have the sufficient practical knowledge and skills to start their first job right away. Moreover, these well prepared college graduates have a higher chance to start their first job with a higher salary because they have already been pre-trained. Providing that a student takes 4 years to graduate, and during the 4 year time period the IVMS enables a student to get at least 1 internship opportunity which allows a student to be hired right at the time of graduation, the social and economic benefits will be huge.

\section{REFERENCES}


1. Alvin, Roth E., "The Art of Designing Markets,” Harvard Business Review, October 2007.

2. Gault, Jack, Evan Leach and Mark Duey, "Effects of business internships on job marketability: the employers' perspective," Education + Training, Vol. 52 No. 1, 2010, pp. 76-88.

3. Stedman, James M. and Lawrence S. Schoenfeld, Kenneth Carroll and Thomas F. Allen, "The Internship Supply-Demand Crisis: Time for a Solution Is Now", Training and Education in Professional Psychology, 2009, Vol. 3, No. 3, 135-139. 